\title{
Sistem Pendukung Keputusan Dalam Menentukan Dosen Pembimbing Skripsi
}

\author{
Iwan Laengge, Hans F. Wowor, Muhamad D. Putro \\ Teknik Informatika Universitas Sam Ratulangi, Manado, Indonesia. \\ iwanlaengge@gmail.com, hanswowor@unsrat.ac.id, dwisnantoputro@unsrat.ac.id
}

\begin{abstract}
Abstrak - Penunjukan dosen pembimbing skripsi di Program Studi Teknik Informatika Universitas Sam Ratulangi Manado saat ini dilakukan dengan cara menentukan secara langsung dengan mempertimbangkan kompetensi, fungsional dan pendidikan dari calon dosen pembimbing. Namun penunjukan dosen pembimbing skripsi secara langsung terkadang mengesampingkan jumlah bimbingan skripsi calon dosen pembimbing skripsi yang mengakibatkan kurang seimbang jumlah bimbingan yang dimiliki oleh setiap dosen dan kurang sesuai dengan tema skripsi yang diajukan oleh mahasiswa, maka dibutuhkan suatu sistem pendukung keputusan yang berguna untuk menentukan dosen pembimbing skripsi, agar supaya skripsi yang diajukan oleh mahasiswa sesuai dengan kompetensi calon dosen pembimbing skripsi dan dosen yang dipilih tidak terlalu banyak jumlah bimbingannya. Tujuan utama dari penelitian ini yaitu membangun aplikasi sistem pendukung keputusan yang dapat menentukan dosen pembimbing skripsi. Metode pengambilan keputusan yang digunakan dalam penelitian ini ialah metode Simple Additive Weighting (SAW. Pengumpulan data dosen dilakukan dengan cara melakukan wawancara terhadap dosen yang masih aktif. Dari hasil pengujian yang dilakukan terhadap sistem, sistem mampu memberikan rekomendasi dosen pembimbing kepada pengguna berdasarkan perhitungan yang dilakukan menggunakan metode SAW, sistem juga menyediakan fitur untuk pemilihan dosen pembimbing skripsi.
\end{abstract}

Kata kunci: SPK, SAW, Penentuan, Dosen, Skripsi.

\section{PENDAHULUAN}

Berdasarkan Peraturan Bersama Menteri Pendidikan dan Kebudayaan dengan Kepala Badan Kepegawaian Negara Nomor 24 Tahun 2014, dijelaskan bahwa Dosen merupakan pendidik profesional dan ilmuwan dengan tugas utama mentransformasikan, mengembangkan, dan menyebarluaskan ilmu pengetahuan, teknologi, dan seni melalui pendidikan, penelitian dan pengabdian kepada masyarakat. Dalam melaksanakan kegiatan pendidikan, dosen memiliki wewenang dan tanggung jawab mengajar dan melakukan bimbingan skripsi.

Skripsi merupakan salah satu persyaratan yang harus ditempuh oleh seorang mahasiswa menjelang akhir studinya. Dalam penyelesaiannya mahasiswa dibimbing oleh tim pembimbing yang bertugas memberikan arahan dan masukan kepada mahasiswa. Proses penyusunan skripsi (karya ilmiah) setiap mahasiswa dibimbing oleh dosen pembimbing sebanyak dua orang atau lebih. Secara tidak langsung dosen pembimbing juga memiliki peran dalam proses penyelesaian penyusunan skripsi tersebut agar bisa selesai dengan tepat waktu.

Penunjukan dosen pembimbing skripsi di Program Studi Teknik Informatika Universitas Sam Ratulangi Manado saat ini dilakukan dengan cara menentukan secara langsung dengan mempertimbangkan kompetensi, fungsional dan pendidikan dari calon dosen pembimbing. Namun penunjukan dosen pembimbing skripsi secara langsung terkadang mengesampingkan jumlah bimbingan skripsi calon dosen pembimbing skripsi yang mengakibatkan kurang seimbang jumlah bimbingan yang dimiliki oleh setiap dosen dan kurang sesuai dengan tema skripsi yang diajukan oleh mahasiswa, maka dibutuhkan suatu sistem pendukung keputusan yang berguna untuk menentukan dosen pembimbing skripsi, agar supaya skripsi yang diajukan oleh mahasiswa sesuai dengan kompetensi calon dosen pembimbing skripsi dan dosen yang dipilih tidak terlalu banyak jumlah bimbingannya. Disamping itu proses penentuan dosen pembimbing skripsi dapat dilakukan dengan mudah. Faktor-faktor yang digunakan untuk penentuan dosen pembimbing skripsi, yaitu pendidikan dosen, pangkat atau fungsional dosen, kompetensi atau bidang keahlian dosen dan jumlah bimbingan skripsi yang masih aktif.

Dengan sistem pendukung keputusan penentuan dosen pembimbing skripsi diharapkan dapat membantu program studi untuk menentukan dosen pembimbing skripsi. Dalam pengembangannya metode Simple Additive Weighting akan digunakan untuk menyelesaikan masalah penentuan dosen pembimbing skripsi.

\section{LANDASAN TEORI}

\section{A. Penelitian Sebelumnya}

Sudah banyak penelitian yang mengangkat tema tentang dosen pembimbing, metode yang digunakan untuk penentuan dosen pembimbing pun bervariasi. Salah satunya penelitian yang dilakukan oleh Pristiwanto yang merupakan dosen dari Sekolah Tinggi Manajemen Informatika dan Komputer (STMIK) Budi Darma Medan pada tahun 2014 dengan judul "Sistem Pendukung Keputusan Dengan Metode Simple 
Additive Weighting Untuk Menentukan Dosen Pembimbing Skripsi". Pada penelitian ini Pristiwanto menerapkan Simple Additive Weighting sebagai metode yang digunakan untuk penentuan pembimbing skripsi, dengan studi kasusnya di STMIK Budi Darma Medan. Menggunakan empat kriteria, yang pertama pendidikan dengan sub kriteria D3, S1, S2 dan S3. Kedua status dengan sub kriteria tetap dan tidak tetap. Ketiga bidang keahlian dengan sub kriteria komputer dan non komputer. Dan keempat golongan dengan sub kriteria IIIA, IIIB, IIIC dan IIID. Bobot dari kriteria dan sub kriteria tersebut dijadikan bahan perhitungan dengan metode SAW. Hasil dari proses perangkingan menggunakan metode SAW dengan nilai bobot terbesar akan direkomendasikan untuk dipilih sebagai dosen pembimbing I atau dosen pembimbing II skripsi.

Pada penelitian ini penulis mengembangkan penelitian sebelumnya yang dilakukan oleh pristiwanto, tetapi dengan studi kasus yang berbeda dari penelitian sebelumnya dan beberapa perbedaan pada kriteria dan sub kriteria yang digunakan. Kriteria yang digunakan pada penelitian ini yaitu pendidikan, fungsional, kompetensi atau bidang keahlian dosen dan kuota bimbingan skripsi. Kriteria pendidikan yang digunakan pada penelitian sebelumnya ada tiga sub kriteria sedangkan pada penelitian ini menggunakan dua sub kriteria, untuk kriteria bidang keahlian pristiwanto menggunakan dua sub kriteria yaitu mengetahui tentang komputer dan tidak mengetahui sedangkan pada penelitian ini digunakan enam sub kriteria yang terdiri dari tematik-tematik skripsi yang sering digunakan dalam penyusunan skripsi di Program Studi Teknik Informatika. Perbedaan juga terdapat pada bahasa pemrograman yang digunakan untuk pengembangan sistem pada penelitian sebelumnya menggunakan bahasa pemrograman desktop sedangkan pada penelitian ini penulis menggunakan bahasa pemrograman WEB.

\section{B. Definisi Sistem}

Sistem adalah suatu prosedur atau elemen yang saling berhubungan satu sama lain dimana dalam sebuah sistem terdapat suatu masukan, proses dan keluaran, untuk mencapai tujuan yang diharapkan.(Mulyanto, 2009).

Dari definisi diatas dapat ditarik kesimpulan bahwa sistem adalah sekumpulan unsur-unsur atau elemen yang saling berhubungan dan saling berinteraksi dengan maksud yang sama untuk mencapai suatu tujuan yang diharapkan.

\section{Definisi Keputusan}

Beberapa definisi keputusan yang dikemukakan oleh para ahli (Hasan Iqbal, M, 2004):

1. Menurut Prof. Dr. Prajudi Atmosudirjo, SH, keputusan adalah suatu pengakhiran daripada proses pemikiran tentang suatu masalah atau problem untuk menjawab pertanyaan apa yang harus diperbuat guna mengatasi masalah tersebut, dengan menjatuhkan pilihan pada suatu alternatif.

2. Menurut James A. F. Stoner, keputusan adalah pemilihan diantara alternatif-alternatif. Definisi ini mengandung tiga pengertian, yaitu:

a. Ada pilihan atas dasar logika atau pertimbangan.

b. Ada beberapa alternatif yang harus dan dipilih salah satu yang terbaik.

c. Ada tujuan yang ingin dicapai, dan kepeputusan itu makin mendekatkan pada tujuan tersebut.

Dari definisi-definisi keputusan diatas dapat ditarik kesimpulan bahwa keputusan merupakan tindakan yang dilakukan setelah melalui proses pemikiran yang bertujuan untuk menjatuhkan suatu pilihan diantara alternatif.-alternatif yang ada.

\section{E. Definisi Sistem Pendukung Keputusan}

Sistem Pendukung Keputusan atau Decision Support System secara umum didefinisikan sebagai sebuah sistem yang mampu memberikan kemampuan baik kemampuan pemecahan masalah maupun kemampuan pengkomunikasian untuk masalah semi terstruktur. Secara khusus, sistem pendukung keputusan didefinisikan sebagai sebuah sistem yang mendukung kerja seorang manajer maupun sekelompok manajer dalam memecahkan masalah semi terstruktur dengan cara memberikan informasi ataupun ulasan menuju pada keputusan tertentu. (Hermawan, 2005).

Kusrini (2007) mendefinisikan sistem pendukung keputusan merupakan sistem informasi interaktif yang menyediakan informasi, pemodelan dan manipulasi data. Sistem itu digunakan untuk membantu pengambilan keputusan dalam situasi yang semi terstruktur dan situasi tidak terstruktur, dimana tak seorang pun tahu secara pasti bagaimana keputusan seharusnya dibuat.

Dari definisi-definisi sistem pendukung keputusan diatas dapat dikatakan bahwa sistem pendukung keputusan merupakan sebuah sistem yang berguna untuk memecahkan sebuah masalah semi terstruktur dan tidak terstruktur yang dapat memudahkan para manajer atau pengambil keputusan melakukan pemilihan pada alternatif yang ada. Sistem pendukung keputusan sendiri tidak sebagai pengganti pengambil keputusan tetapi lebih kepada pemberi saran untuk pemecahan suatu masalah.

\section{F. Fuzzy Multiple Attribute Decision Making (FMADM)}

Menurut Kusumadewi, S. dkk (2006) Fuzzy Multiple Attribute Decision Making (FMADM) merupakan suatu metode yang digunakan untuk mencari alternatif optimal dari sejumlah alternatif dengan kriteria tertentu. Inti dari FMADM adalah menentukan nilai bobot untuk setiap atribut, kemudian dilanjutkan dengan proses perangkingan yang akan menyeleksi alternatif yang sudah diberikan. Pada dasarnya, ada 3 pendekatan untuk mencari nilai bobot atribut, yaitu pendekatan subjektif, pendekatan objektif dan pendekatan integrasi antara subjektif dan objektif. Masing-masing pendekatan memiliki kelebihan dan kelemahan. Pada pendekatan subjektif, nilai bobot ditentukan berdasarkan subjektifitas dari para pengambil keputusan sehingga beberapa 
faktor dalam proses perangkingan alternatif bisa ditentukan secara bebas. Sedangkan pada pendekatan objektif nilai bobot dihitung secara matematis sehingga mengabaikan subjektifitas dari pengambil keputusan.

Kusumadewi, S. dkk (2006) menuturkan ada beberapa metode yang dapat digunakan untuk menyelesaikan masalah FMADM. Antara lain:

1. Simple Additive Weighting (SAW).

2. Weighted Product (WP).

3. ELECTRE.

4. Technique for Order Preference by Similarity to Ideal Solution (TOPSIS).

5. Analytic Hierarchy Process (AHP).

\section{G. Simple Additive Weighting (SAW)}

Menurut Kusumadewi, S. dkk (2006) Simple Additive Weighting sering juga dikenal istilah metode penjumlahan terbobot. Konsep dasar metode SAW adalah mencari penjumlahan terbobot dari rating kinerja pada setiap alternatif pada semua atribut. Metode SAW membutuhkan proses normalisasi matriks keputusan (X) ke suatu skala yang dapat diperbandingkan dengan semua rating alternatif yang ada.

Kusumadewi, S. dkk (2006) menuturkan persamaanpersamaan yang ada dalam metode SAW, sebagai berikut:

$$
r_{i j}= \begin{cases}\frac{x_{i j}}{\operatorname{Max} x_{i j}} & \text { Jika } j \text { adalah atribut keuntungan(benefit) } \\ \frac{\operatorname{Min} x_{i j}}{x_{i j}} & \text { Jika } j \text { adalah atribut biaya (cost) }\end{cases}
$$

Keterangan:

rij = Rating kinerja ternormalisasi dari alternatif $\mathrm{Ai}$ pada kriteria $\mathrm{Cj}$.

xij = Nilai atribut yang dimiliki dari setiap kriteria.

Max xij= Nilai terbesar jika yang dicari adalah atribut keuntungan atau nilai tertinggi.

Min $x i j=$ Nilai min jika yang dicari adalah biaya atau nilai terendah.

Nilai preferensi untuk setiap alternatif (Vi) diberikan sebagai :

$$
V_{i}=\sum_{j=1}^{n} W_{j} r_{i j}
$$

Keterangan:

$\mathrm{Vi} \quad=$ Ranking untuk setiap alternatif

$\mathrm{Wj} \quad=$ Nilai bobot dari setiap kriteria

rij $\quad=$ Nilai rating kinerja

Nilai Vi yang lebih besar mengindikasikan bahwa alternatif Ai lebih terpilih.

\section{METODELOGI PENELITIAN}

\section{A. Metode Pengumpulan Data}

Metode pengumpulan data merupakan tahapan untuk mengumpulkan data maupun teori-teori yang berkaitan dengan penelitian yang sedang dilakukan.
1. Studi Literatur dilakukan untuk mempelajari penelitianpenelitian sebelumnya yang berhubungan dengan Sistem Pendukung Keputusan menggunakan metode Simple Additive Weighting.

2. Wawancara dilakukan untuk memenuhi kebutuhan data dan kebutuhan sistem.

\section{B. Metode Pengambilan Keputusan}

Metode pengambilan keputusan yang digunakan pada penelitian ini menggunakan salah satu metode yang ada di Fuzzy Multiple Attribute Decision Making yaitu metode Simple Additive Weighting.

Terdapat beberapa fase pada metode SAW diantaranya, melakukan penentuan kriteria dan sub kriteria, melakukan pembobotan pada setiap kriteria dan sub kriteria, hasil pembobotan kriteria dan sub kriteria menghasilkan matriks keputusan X, kemudian melakukan normalisasi matriks keputusan $\mathrm{X}$ menggunakan persamaan 1 dan dari hasil normalisasi (matriks keputusan $\mathrm{R}$ ) dilakukan proses perangkingan menggunakan persamaan 2 .

Gambar 1 merupakan gambaran proses dari metode Simple Additive Weighting dalam menentukan alternatif dosen pembimbing skripsi terbaik.

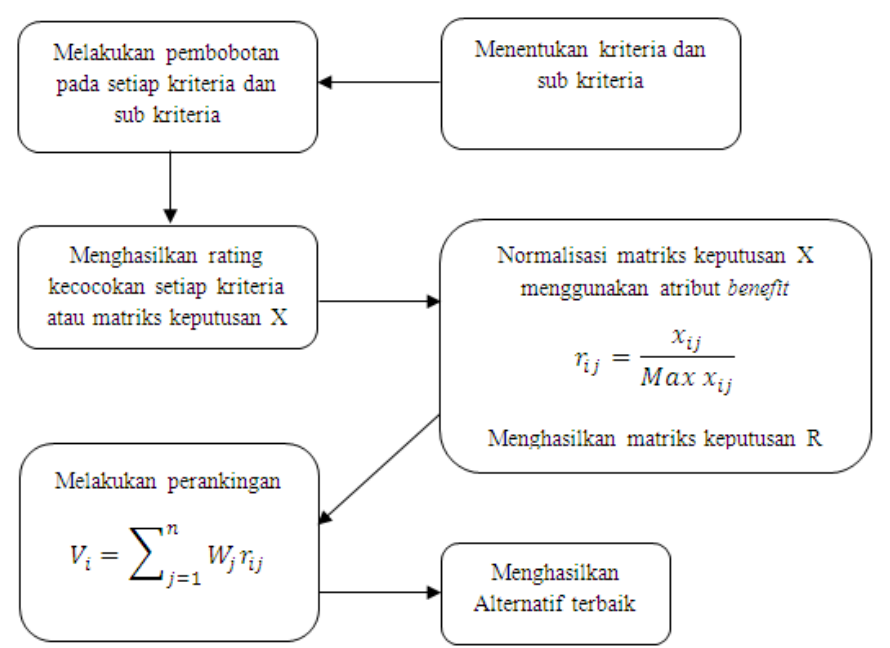

\section{Gambar 1 Proses Pengambilan Keputusan}

Berdasarkan gambar 1 dapat dijelaskan secara rinci, sebagai berikut:

1. Pada penelitian ini terdapat 4 (empat) kriteria dan sub kriteria yang menjadi acuan penentuan dosen pembimbing skripsi, yaitu pendidikan dosen, fungsional dosen, kompetensi atau bidang keahlian dosen dan kuota bimbingan skripsi.

2. Pada tahap ini kriteria dan sub kriteria yang telah ditentukan sebelumnya diberi bobot.

3. Matriks keputusan $\mathrm{X}$ dihasilkan dari data dosen calon pembimbing skripsi berdasarkan kriteria yang ada.

4. Normalisasi dari matriks keputusan $X$ atau data calon dosen pembimbing skripsi menggunakan persamaan $r_{i j}=\frac{x_{i j}}{\operatorname{Max} x_{i j}}$, pada penelitian ini semua kriteria yang digunakan menggunakan atribut benefit dalam 
melakukan normalisasi matriks keputusan X. Setelah normalisasi dilakukan menghasilkan matriks keputusan $\mathrm{R}$.

5. Pada tahap ini dilakukan perangkingan matriks keputusan $\mathrm{R}$ atau hasil dari normalisasi matriks keputusan $\mathrm{X}$ menggunakan persamaan $V_{i}=\sum_{j=1}^{n} W_{j} r_{i j}$.

6. Hasil akhir dari proses perangkingan menghasilkan alternatif terbaik dari calon dosen pembimbing skripsi.

\section{Pengembangan Sistem}

Pengembangan sistem merupakan tahapan pengaplikasian rumus metode SAW ke dalam kode program, sistem dikembangkan menggunakan salah satu bahasa pemrograman WEB yaitu PHP dan menggunakan Database MySQL.

\section{HASIL DAN PEMBAHASAN}

\section{A. Penentuan Kriteria}

Dalam menentukan dosen pembimbing skripsi dibutuhkan kriteria yang nantinya setiap alternatif yang ada akan dibandingkan berdasarkan kriteria-kriteria tersebut. Dari hasil konsultasi dengan dosen pembimbing skripsi dan Ketua Program Studi Teknik Informatika yang dalam hal ini adalah pengambil keputusan. Berikut adalah kriteria yang digunakan untuk menentukan dosen pembimbing skripsi:

Tabel 1 Kriteria dan Sub Kriteria

\begin{tabular}{|c|c|}
\hline Kriteria & Sub Kriteria \\
\hline \multirow{2}{*}{ Pendidikan } & S2 \\
\hline & S3 \\
\hline \multirow{5}{*}{ Fungsional } & Tenaga Pengajar \\
\hline & Asisten Ahli \\
\hline & Lektor \\
\hline & Lektor Kepala \\
\hline & Guru Besar \\
\hline \multirow{6}{*}{ Kompetensi } & Rekayasa Perangkat Lunak (RPL) \\
\hline & $\begin{array}{l}\text { Sistem Cerdas \& Sistem Pendukung } \\
\text { Keputusan (SC \& SPK) }\end{array}$ \\
\hline & Sistem Informasi (SI) \\
\hline & Jaringan \\
\hline & Mobile \\
\hline & Multimedia \\
\hline \multirow{5}{*}{$\begin{array}{l}\text { Kuota atau Jumlah } \\
\text { Bimbingan }\end{array}$} & $21-25$ \\
\hline & $16-20$ \\
\hline & $11-15$ \\
\hline & $6-10$ \\
\hline & $0-5$ \\
\hline
\end{tabular}

B. Pembobotan Kriteria dan Sub Kriteria

Pembobotan kriteria dan sub kriteria ditentukan secara subjektif. Berikut hasil pembobotannya:

Tabel 2 Bobot

\begin{tabular}{|c|c|}
\hline Kategori & Nilai \\
\hline Sangat Rendah & 0 \\
\hline Rendah & 0.25 \\
\hline Sedang & 0.5 \\
\hline Tinggi & 0.75 \\
\hline Sangat Tinggi & 1 \\
\hline
\end{tabular}

Tabel 3 Kriteria dan Bobot Kriteria

\begin{tabular}{|c|c|c|}
\hline Kriteria & Keterangan & Nilai \\
\hline $\mathrm{C} 1$ & Pendidikan & 0.25 \\
\hline $\mathrm{C} 2$ & Golongan & 1 \\
\hline $\mathrm{C} 3$ & Kompetensi & 0.5 \\
\hline $\mathrm{C} 4$ & Kuota & 0.75 \\
\hline
\end{tabular}

Tabel 4 Sub Kriteria Pendidikan

\begin{tabular}{|c|c|c|}
\hline Pendidikan & Kategori & Nilai \\
\hline S2 & Memenuhi & 0.5 \\
\hline S3 & Sangat Memenuhi & 1 \\
\hline
\end{tabular}

Tabel 5 Sub Kriteria Fungsional

\begin{tabular}{|c|c|c|}
\hline Fungsional & Kategori & Nilai \\
\hline Tenaga Pengajar & Sangat Kurang & 0 \\
\hline Asisten Ahli & Kurang & 0.25 \\
\hline Lektor & Cukup & 0.5 \\
\hline Lektor Kepala & Baik & 0.75 \\
\hline Guru Besar & Sangat Baik & 1 \\
\hline
\end{tabular}

Tabel 6 Sub Kriteria Kompetensi

\begin{tabular}{|c|c|c|}
\hline \multirow{4}{*}{ Kompetensi } & Kategori & Nilai \\
\cline { 2 - 3 } & Tingkat 6 & 0.16 \\
\cline { 2 - 3 } & Tingkat 5 & 0.33 \\
\cline { 2 - 3 } & Tingkat 4 & 0.5 \\
\cline { 2 - 3 } & Tingkat 3 & 0.67 \\
\cline { 2 - 3 } & Tingkat 2 & 0.83 \\
\cline { 2 - 3 } & Tingkat 1 & 1 \\
\hline
\end{tabular}


Tabel 7 Sub Kriteria Kuota

\begin{tabular}{|c|c|c|}
\hline Kuota & Kategori & Nilai \\
\hline $21-25$ & Sangat Banyak & 0 \\
\hline $16-20$ & Banyak & 0.25 \\
\hline $11-15$ & Cukup & 0.5 \\
\hline $6-10$ & Kurang & 0.75 \\
\hline $0-5$ & Sangat Kurang & 1 \\
\hline
\end{tabular}

C. Data Calon Dosen Pembimbing

Data calon dosen pembimbing didapat dari hasil wawancara. Tabel 8 merupakan sampel data calon dosen pembimbing.

Tabel 8 Data Calon Dosen Pembimbing

\begin{tabular}{|c|c|c|c|c|}
\hline$\#$ & Pendidikan & Fungsional & Kompetensi & Kuota \\
\hline A1 & S2 & Lektor & Jaringan & Kurang \\
\hline A2 & S3 & $\begin{array}{c}\text { Asisten } \\
\text { Ahli }\end{array}$ & Jaringan & $\begin{array}{c}\text { Sangat } \\
\text { Kurang }\end{array}$ \\
\hline A3 & S2 & $\begin{array}{c}\text { Lektor } \\
\text { Kepala }\end{array}$ & SI & Kurang \\
\hline A4 & S2 & $\begin{array}{c}\text { Asisten } \\
\text { Ahli }\end{array}$ & SC \& SPK & Kurang \\
\hline A5 & S2 & Lektor & RPL & Banyak \\
\hline
\end{tabular}

Tabel 9 merupakan data sampel kompetensi dosen pembimbing. Data kompetensi didapatkan dari hasil wawancara.

Tabel 9 Data Kompetensi Calon Dosen Pembimbing

\begin{tabular}{|c|c|c|c|c|c|c|}
\hline \multirow{2}{*}{$\#$} & \multicolumn{6}{|c|}{ Kompetensi } \\
\cline { 2 - 7 } & RPL & $\begin{array}{c}\text { SC } \\
\text { SPK }\end{array}$ & SI & Jaringan & Mobile & $\begin{array}{c}\text { Multi } \\
\text { media }\end{array}$ \\
\hline A1 & 0.16 & 0.5 & 0.67 & 1 & 0.83 & 0.33 \\
\hline A2 & 0.83 & 0.16 & 0.33 & 1 & 0.67 & 0.5 \\
\hline A3 & 0.83 & 0.5 & 1 & 0.16 & 0.33 & 0.67 \\
\hline A4 & 0.16 & 1 & 0.33 & 0.67 & 0.83 & 0.5 \\
\hline A5 & 1 & 0.83 & 0.67 & 0.16 & 0.33 & 0.5 \\
\hline
\end{tabular}

D. Perhitungan Metode SAW

Berikut contoh kasus perhitungan menggunakan metode SAW dengan kompetensi dosen SC \& SPK. Tabel 10 merupakan matriks awal.
Tabel 10 Matriks Awal

$\begin{array}{cccc}0.5 & 0.5 & 0.5 & 0.75 \\ 1 & 0.25 & 0.16 & 1 \\ 0.5 & 0.75 & 0.5 & 0.75 \\ 0.5 & 0.25 & 1 & 0.75 \\ 0.5 & 0.5 & 0.83 & 0.5\end{array}$

Berdasarkan tabel 10 yang merupakan tabel matriks awal selanjutnya dilakukan normalisasi matriks. Karena normalisasinya menggunakan atribut Benefit maka nilai tertinggi tinggi didalam matriks yang sangat diprioritaskan. Nilai tertinggi kriteria $\mathrm{C} 1=1$, nilai tertinggi kriteria $\mathrm{C} 2=$ 0.75 , nilai tertinggi kriteria $\mathrm{C} 3=1$ dan nilai tertinggi $\mathrm{C} 4=1$.

a. Normalisasi Kriteria Pendidikan (C1)

$$
\begin{aligned}
& r_{A 1 C 1}=\frac{0.5}{\operatorname{Max}\{0.5 ; 0.5 ; 0.5 ; 0.5 ; 1\}}=\frac{0.5}{1}=0.5 \\
& r_{A 2 C 1}=\frac{1}{\operatorname{Max}\{0.5 ; 0.5 ; 0.5 ; 0.5 ; 1\}}=\frac{1}{1}=1 \\
& r_{A 3 C 1}=\frac{0.5}{\operatorname{Max}\{0.5 ; 0.5 ; 0.5 ; 0.5 ; 1\}}=\frac{0.5}{1}=0.5 \\
& r_{A 4 C 1}=\frac{0.5}{\operatorname{Max}\{0.5 ; 0.5 ; 0.5 ; 0.5 ; 1\}}=\frac{0.5}{1}=0.5 \\
& r_{A 5 C 1}=\frac{0.5}{\operatorname{Max}\{0.5 ; 0.5 ; 0.5 ; 0.5 ; 1\}}=\frac{0.5}{1}=0.5
\end{aligned}
$$

b. Normalisasi Kriteria Fungsional (C2)

$$
\begin{aligned}
& r_{A 1 C 2}=\frac{0.5}{\operatorname{Max}\{0.5 ; 0.5 ; 0.75 ; 0.25 ; 0.25\}}=\frac{0.5}{0.75}=0.67 \\
& r_{A 2 C 2}=\frac{0.25}{\operatorname{Max}\{0.5 ; 0.5 ; 0.75 ; 0.25 ; 0.25\}}=\frac{0.25}{0.75}=0.33 \\
& r_{A 3 C 2}=\frac{0.75}{\operatorname{Max}\{0.5 ; 0.5 ; 0.75 ; 0.25 ; 0.25\}}=\frac{0.75}{0.75}=1 \\
& r_{A 4 C 2}=\frac{0.25}{\operatorname{Max}\{0.5 ; 0.5 ; 0.75 ; 0.25 ; 0.25\}}=\frac{0.25}{0.75}=0.33 \\
& r_{A 5 C 2}=\frac{0.5}{\operatorname{Max}\{0.5 ; 0.5 ; 0.75 ; 0.25 ; 0.25\}}=\frac{0.5}{0.75}=0.67
\end{aligned}
$$

c. Normalisasi Kriteria Kompetensi (C3)

$$
\begin{aligned}
& r_{A 1 C 3}=\frac{0.5}{\operatorname{Max}\{0.83 ; 0.5 ; 0.5 ; 1 ; 0.16\}}=\frac{0.5}{1}=0.5 \\
& r_{A 2 C 3}=\frac{0.16}{\operatorname{Max}\{0.83 ; 0.5 ; 0.5 ; 1 ; 0.16\}}=\frac{0.16}{1}=0.16 \\
& r_{A 3 C 3}=\frac{0.5}{\operatorname{Max}\{0.83 ; 0.5 ; 0.5 ; 1 ; 0.16\}}=\frac{0.5}{1}=0.5 \\
& r_{A 4 C 3}=\frac{1}{\operatorname{Max}\{0.83 ; 0.5 ; 0.5 ; 1 ; 0.16\}}=\frac{1}{1}=1 \\
& r_{A 5 C 3}=\frac{0.83}{\operatorname{Max}\{0.83 ; 0.5 ; 0.5 ; 1 ; 0.16\}}=\frac{0.83}{1}=0.83
\end{aligned}
$$


d. Normalisasi Kriteria Kuota (C4)

$$
\begin{aligned}
& r_{A 1 C 4}=\frac{0.75}{\operatorname{Max}\{0.5 ; 0.75 ; 0.75 ; 0.75 ; 1\}}=\frac{0.75}{1}=0.75 \\
& r_{A 2 C 4}=\frac{1}{\operatorname{Max}\{0.5 ; 0.75 ; 0.75 ; 0.75 ; 1\}}=\frac{1}{1}=1 \\
& r_{A 3 C 4}=\frac{0.75}{\operatorname{Max}\{0.5 ; 0.75 ; 0.75 ; 0.75 ; 1\}}=\frac{0.75}{1}=0.75 \\
& r_{A 4 C 4}=\frac{0.75}{\operatorname{Max}\{0.5 ; 0.75 ; 0.75 ; 0.75 ; 1\}}=\frac{0.75}{1}=0.75 \\
& r_{A 5 C 4}=\frac{0.5}{\operatorname{Max}\{0.5 ; 0.75 ; 0.75 ; 0.75 ; 1\}}=\frac{0.5}{1}=0.5
\end{aligned}
$$

Berdasarkan hasil normalisasi matriks awal atau matriks keputusan X menghasilkan matriks R. Tabel 11 merupakan matriks hasil normalisasi atau matriks $\mathrm{R}$.

Tabel 11 Matriks Normalisasi (R)

$\begin{array}{|cccc|}0.5 & 0.67 & 0.5 & 0.75 \\ 1 & 0.33 & 0.16 & 1 \\ 0.5 & 1 & 0.5 & 0.75 \\ 0.5 & 0.33 & 1 & 0.75 \\ 0.5 & 0.67 & 0.83 & 0.5\end{array}$

Setelah menghasilkan matriks $\mathrm{R}$, selanjutnya dilakukan perangkingan menggunakan persamaan 2 . Bobot preferensi (W) yang digunakan berdasarkan tabel 3 yaitu $\mathrm{W}=[0.25 ; 1$; $0.5 ; 0.75]$. Berikut proses perangkingannya:

$V_{A 1}=(0.25)(0.5)+(1)(0.67)+(0.5)(0.5)+(0.75)(0.75)=$ $0.13+0.67+0.25+0.56=1.61$

$V_{A 2}=(0.25)(1)+(1)(0.33)+(0.5)(0.16)+(0.75)(1)=0.25+$ $0.33+0.08+0.75=1.41$

$V_{A 3}=(0.25)(0.5)+(1)(1)+(0.5)(0.5)+(0.75)(0.75)=0.13+$ $1+0.25+0.56=1.94$

$V_{A 4}=(0.25)(0.5)+(1)(0.33)+(0.5)(1)+(0.75)(0.75)=$

$0.13+0.33+0.5+0.56=1.52$

$V_{A 5}=(0.25)(0.5)+(1)(0.67)+(0.5)(0.83)+(0.75)(0.5)=$

$0.13+0.67+0.42+0.38=1.6$

Berdasarkan hasil perhitungan di atas menghasilkan alternatif terbaik dosen pembimbing skripsi. Berikut tabel 12 merupakan hasil perangkingan:

Tabel 12 Hasil Perangkingan

\begin{tabular}{|c|c|}
\hline Alternatif & Hasil \\
\hline $\mathrm{A} 3$ & 1.94 \\
\hline $\mathrm{A} 1$ & 1.61 \\
\hline $\mathrm{A} 5$ & 1.6 \\
\hline $\mathrm{A} 4$ & 1.52 \\
\hline $\mathrm{A} 2$ & 1.41 \\
\hline
\end{tabular}

E. Implementasi Sistem

Berikut implementasi sistem untuk perhitungan metode SAW dari sistem yang telah dikembangkan:

a. Halaman Utama Sistem

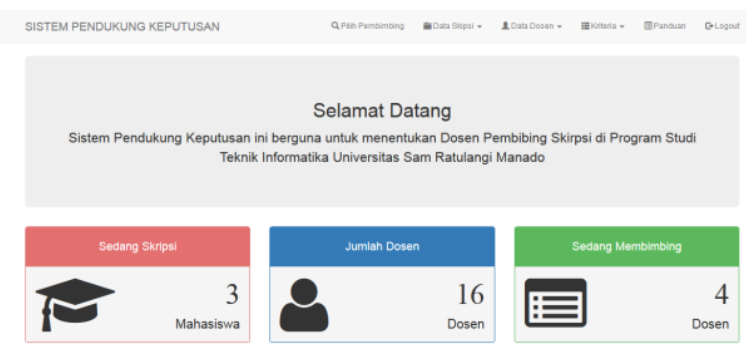

Gambar 2 Halaman Utama

Halaman utama menampilkan informasi tentang jumlah mahasiswa, jumlah dosen, dan jumlah dosen yang sedang membimbing.

b. Halaman Pilih Pembimbing

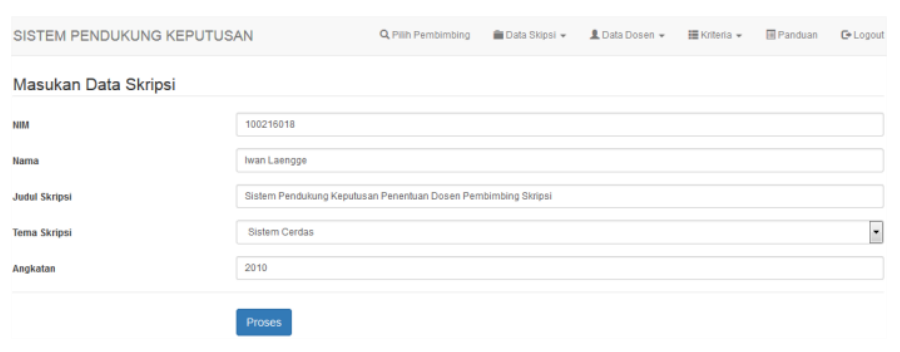

Gambar 3 Halaman Pilih Pembimbing

Halaman pilih pembimbing berfungsi untuk melakukan penginputan data skripsi dan melakukan pemilihan dosen pembimbing berdasarkan hasil perhitungan menggunakan metode SAW.

c. Matriks Awal

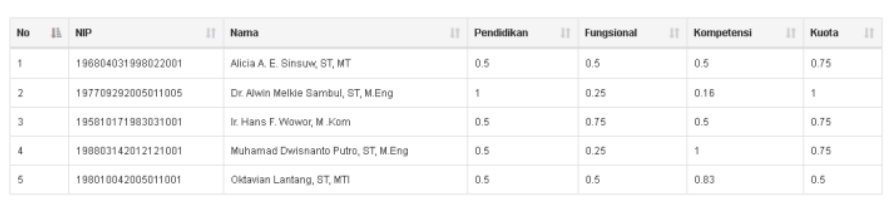

Gambar 4 Tabel Matriks Awal

Matriks awal merupakan tampilan tabel matriks awal pada sistem yang nantinya dilakukan normalisasi matriks.

d. Normalisasi

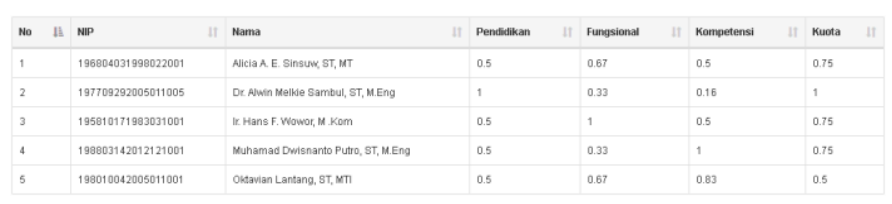

Gambar 5 Tabel Normalisasi

Normalisasi merupakan tabel hasil normalisasi matriks awal menggunakan persamaan 1 dengan atribut Bennefit. 
e. Hasil Ranking

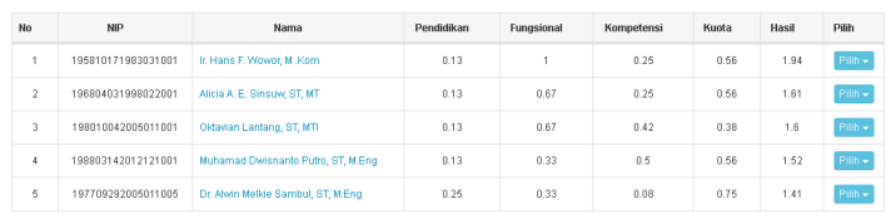

Gambar 6 Tabel Hasil Ranking

Hasil ranking merupakan tabel hasil perhitungan menggunakan persamaan 2 .

\section{PENUTUP}

\section{A. Kesimpulan}

Berdasarkan hasil dan pembahasan pada bab sebelumnya, penulis menarik kesimpulan:

1. Sistem pendukung keputusan penentuan dosen pembimbing skripsi yang dikembangkan dapat mengimplementasikan metode Simple Additive Weighting.

2. Berdasarkan hasil pengujian, perhitungan yang dilakukan oleh sistem pendukung keputusan penentuan dosen pembimbing skripsi telah sesuai dengan perhitungan yang dilakukan secara manual.

B. Saran

Sistem pendukung keputusan penentuan dosen pembimbing skripsi menggunakan metode Simple Additive Weighting yang dikembangkan masih jauh dari sempurna. Berikut saran untuk penelitian selanjutnya:

1. Diharapkan sistem dapat dikembangkan lebih dinamis lagi pada kriteria, agar pengguna dapat menambah kriteria baru dengan lebih mudah.

2. Diharapkan sistem dapat dikembangkan lebih luas lagi dalam penentuan dosen pembimbing tidak hanya pada lingkungan program studi tetapi pada lingkungan jurusan juga.

\section{DAFTAR PUSTAKA}

[1] Hasan Iqbal, M. 2004. Pokok-Pokok Materi Teori Pengambilan Keputusan. Ghalia Indonesia. Bogor Selatan.

[2] Hermawan, J. 2005. Membangun Decision Support System. Andi. Yogyakarta.

[3] Kusumadewi, Sri, Sri Hartati, Agus Harjoko dan Retantyo Wardoyo. 2006. Fuzzy Multi-Atrribute Decision Making (Fuzzy MADM). Graha Ilmu. Yogyakarta.

[4] Kusrini. 2007. Konsep dan Aplikasi Sistem Pendukung Keputusan. Andi. Yogyakarta.
[5] Mulyanto, Agus. 2009. Sistem Informasi Konsep dan Aplikasi. Pustaka Pelajar. Yogyakarta.

[6] Peraturan Bersama Menteri Pendidikan dan Kebudayaan dengan Kepala Badan Kepegawaian Negara No.24 Tahun 2014.

[7] Pristiwanto. 2014. Sistem Pendukung Keputusan Dengan Metode Simple Additive Weighting Untuk Menentukan Dosen Pembimbing Skripsi. Vol 2, No 1.

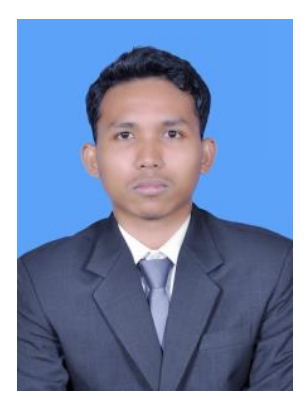

Penulis bernama Iwan Laengge, lahir di Desa Parigi Kecamatan Taliabu Timur, Kabupaten Kepulauan Taliabu, Provinsi Maluku Utara pada tanggal 26 November 1993, penulis merupakan anak keempat dari 5 bersaudara. Penulis memulai pendidikan pada Tingkat Sekolah Dasar di SD Alhilaal Parigi sekarang sudah menjadi SD Negeri Parigi pada tahun 1998 dan dinyatakan lulus pada tahun 2004. Di tahun yang sama penulis melanjutkan pendidikan pada tingkat SLTP di Madrasah Tsanawiyah Negeri Kota Ternate dan dinyatakan lulus pada tahun 2007. Di tahun yang sama pula penulis melanjutkan pendidikan di Sekolah Menengah Kejuruan Negeri 2 Kota Ternate dan dinyatakan lulus pada tahun 2010. Kemudian pada tahun 2010 penulis diterima di Fakultas Teknik Jurusan Teknik Elektro Program Studi Teknik Informatika Universitas Sam Ratulangi Manado dan dinyatakan lulus pada tahun 2016. 